\title{
Effects of a Rebamipide Mouthwash on Stomatitis Caused by Cancer Chemotherapy -Evaluation of the Efficacy by Patients Themselves-
}

\author{
Naoko Ishii, ${ }^{* a, b}$ Yayoi Kawano, ${ }^{b}$ Hideki Sakai, ${ }^{c}$ Seitaku Hayashi, ${ }^{d}$ \\ Norikazu Akizuki, ${ }^{e}$ Masayo Komoda, ${ }^{b}$ and Takehisa Hanawa ${ }^{b}$ \\ aDepartment of Pharmacy, Kashiwa City Hospital; 1-3 Fuse, Kashiwa, Chiba 277-0825, Japan: ${ }^{b}$ Faculty of \\ Pharmaceutical Sciences, Tokyo University of Science; 2641 Yamazaki, Noda, Chiba 278-8510, Japan: \\ cDepartment of Gastroenterological Medicine, Kashiwa City Hospital; 1-3 Fuse, Kashiwa, Chiba 277-0825, \\ Japan: ${ }^{d}$ Department of Surgery, Kashiwa City Hospital; 1-3 Fuse, Kashiwa, Chiba 277-0825, Japan: and \\ eDepartment of Respiratory Medicine, Kashiwa City Hospital, 1-3 Fuse, Kashiwa, Chiba 277-0825, Japan.
}

(Received February 15, 2017; Accepted March 20, 2017; Advance publication released online May 11, 2017)

\begin{abstract}
Anticancer drug-induced stomatitis develops in $30 \%$ to $40 \%$ of cancer cases that undergo chemotherapy. However, medications for this condition are not commercially available in Japan. Upon obtaining approval of the ethics committee, a mouthwash containing rebamipide as the active ingredient (rebamipide mouthwash) was administered to one inpatient and four outpatients, who had developed stomatitis caused by cancer chemotherapy. Starting from $14 \mathrm{~d}$ after the administration of the rebamipide mouthwash, the patients scored a stomatitis survey on oral state, pain level, and diet and recorded the number of times they gargled, as well as any stomatitis observations, in a stomatitis diary. The total scores for the points for each of the three types of survey sections were classified into Grades 0 to 4 and evaluated as a stomatitis evaluation score (SES). The SES became " 0 "' in three out of the five patients within $14 \mathrm{~d}$ of treatment. No change in SES was found in one patient. In the remaining patients, SES became " 0 ”' once but increased again later. Using image analysis software (ImageJ), the area at which the stomatitis was observed was measured. When comparing SES and change in the area in patients who agreed to participate, gradual reductions in the extent of stomatitis was observed even during the period when SES did not change. Having patients fill in an observation chart was effective for grasping changes in symptoms in outpatients.
\end{abstract}

Key words_— stomatitis; rebamipide mouthwash; chemotherapy; ImageJ; anticancer agent

\section{INTRODUCTION}

Among the potential adverse reactions caused by cancer chemotherapy, stomatitis is said to develop in $30-40 \%$ of cases administered anticancer drugs, 70 $90 \%$ of cases that undergo hematopoietic stem cell transplantation, and almost all cases that undergo radiotherapy and receive anticancer drugs. ${ }^{1)}$ Stomatitis caused by cancer chemotherapy is thought to primarily result from mucosal damage and a secondary infection. Mucosal damage is induced by reactive oxygen species, which are generated by anticancer drugs by inhibiting cellular biochemical metabolic pathways. Secondary infections are associated with decreased immune competence due to higher rates of mouth infections, undernutrition, and myelosuppression. ${ }^{2)}$ In addition, stomatitis involves both distress and pain, as well as anorexia, sleep disturbance, mental distress, and other serious medical conditions. This may further decrease the quality of life and have

\footnotetext{
*e-mail: ishii@ kashiwacity-hp.or.jp
}

a serious impact on the continuation of cancer chemotherapy.

For the prevention of stomatitis, the importance of thorough and ongoing hygiene control, such as maintenance of oral hygiene has been established. ${ }^{3)}$ However, it is difficult to achieve complete prevention with hygiene control alone. According to a previous study conducted in the US, keratinocyte growth factor was found to inhibit the onset of anticancer druginduced stomatitis. ${ }^{4,5)}$ Currently, there are no commercially available medications for stomatitis caused by anticancer drugs in Japan, where treatment methods for the condition remain to be established. Thus, symptomatic treatment (e.g., gargling with sodium azulene sulfonate and oral cryotherapy with ice chips) has conventionally been performed.6,7) For the purpose of pain relief, treatments including opioids, lidocaine, and indomethacin spray have been used. ${ }^{8-10)}$ A mouthwash containing camostat mesylate or allopurinol, which shows inhibitory effects on reactive oxygen species generation, has been reported to be effective as an in-house formulation. ${ }^{11-15)}$ Of these, 
allopurinol inhibits 5-FU phosphorylation; thus, the number of eligible cases were expected to be limited. ${ }^{11)}$ Therefore, we used the mouthwash containing camostat mesylate at the Kashiwa City Hospital for a successful treatment outcome. ${ }^{16)}$ However, a mouthwash with camostat mesylate tastes unpleasant, which is attributed to the bitterness of the active ingredient and foul taste of carboxymethylcellulose (CMC-Na), a thickening agent. Therefore, gargling with sodium bicarbonate $30 \mathrm{~min}$ after gargling with the formulation was necessary to reduce discomfort. ${ }^{17)} \mathrm{CMC}-\mathrm{Na}$ is usually added to extend the retention time of the active ingredients in the mouth; however, the occurrence of adverse events due to the ingestion of camostat mesylate in the body is a concern. In this context, a new mouthwash replacing these dispersion media and active ingredients has been sought. ${ }^{17-20)}$

Rebamipide has an inhibitory effect on reactive oxygen species generation and is commonly used as a drug to treat gastric ulcers and acute and chronic gastritis. ${ }^{21,22)}$ According to reports, the oral administration of rebamipide is effective for canker sores ${ }^{23)}$ and recurrent aphthous stomatitis, which is an essential diagnostic criterion for Behcet's syndrome. ${ }^{24)}$ Furthermore, since the preventive effects of rebamipide on stomatitis were reported by Kawata et al., some medical institutions have used mouthwash with rebamipide as the active ingredient. ${ }^{25,26)}$ However, reports on the treatment response are limited. Thus, we administered a rebamipide mouthwash to cases of stomatitis caused by cancer chemotherapy and verified its treatment effects. Shinohara et al., comprehensively investigated the efficacy of rebamipide mouthwash against chemotherapy induced oral stomatitis (CIOS), and demonstrated that rebamipide mouthwash has significant therapeutic efficacy against CIOS. ${ }^{26)}$ Their investigation was carried out by interviewing to patients based on the National Cancer Institute's Common Terminology Criteria for Adverse Events (CTCAE Ver. 4.0). In order to obtain the objective answers, Kawata et al., demonstrated that these assessments should be carried out by the specific pharmacists such as the pharmacists embarking on the inpatient pharmaceutical service. ${ }^{25)}$ The adverse effect due to the cancer treatment have been mainly evaluated by medical staff. Meanwhile, in recent years, outpatient chemotherapy has been widely done in many medical institutions. Since the exact
Table 1. Composition of the Rebamipide Mouthwash

\begin{tabular}{clc}
\hline \hline Rp. & Rebamipide $^{\mathrm{a}}$ & $600 \mathrm{mg}$ \\
& Citric acid & $0.45 \mathrm{~g}$ \\
L-glutamine $^{\circledR}$ & $1.50 \mathrm{~g}$ \\
Simple syrup & $12.0 \mathrm{~mL}$ \\
Toromeiku $^{\circledR}$ clear $^{\mathrm{b}}$ & $1.50 \mathrm{~g}$ \\
Preservative $^{\mathrm{c}}$ & $2.0 \mathrm{~mL}$ \\
Distilled water & Total amount $300 \mathrm{~mL}$ \\
\hline
\end{tabular}

a It was prepared by grinding the Mucosta ${ }^{\circledR}$ tablets $(100 \mathrm{mg})$, and weighed the ground products corresponding as $600 \mathrm{mg}$ of rebamipide. ${ }^{\mathrm{b}}$ Includes dextrin and polysaccharide thickener and potassium chloride. c Includes $0.08 \mathrm{~g}$ of methyl $p$-hydroxybenzoate and $0.04 \mathrm{~g}$ of propyl $p$ hydroxybenzoate in $2 \mathrm{~mL}$ of ethanol.

grasp of adverse effect by medical staff has been difficult, the new criteria for evaluating by patients themselves has been required.

In this study, we attempted to assess by using ImageJ, which is biological software, in addition to the CTCAE Ver. 4.0 score to obtain more objective assessment.

\section{METHODS}

Subjects Patients with stomatitis who underwent cancer chemotherapy at the Kashiwa City Hospital from November 2012 to December 2015 were eligible for this study. Of these, patients who gave their written informed consent were included in this study. This study was conducted in compliance with the "Ethical Guidelines for Medical and Health Research Involving Human Subjects". The approval for the conduct of this study was obtained from the ethical review committee of our hospital, with the approval numbers: $24-4$ (registration date : $25 / 6 / 2012$ ), 25-4 (registration date :27/5/2013), 26-3 (registration date :29/5/2014), and 27-1 (registration date : 27/5/2015).

Description of Materials The concentration of rebamipide, the active ingredient of the rebamipide mouthwash, was determined based on the methods established by Kawata et al. ${ }^{25)}$ Component of rebamipide mouthwash was shown in Table 1. Mucosta ${ }^{\circledR}$ tablets $100 \mathrm{mg}$ (Otsuka Pharmaceutical Co., Ltd., Tokyo) were grand for $30 \mathrm{~s}$ with a tablet crushing machine (Iwatani Corporation, Tokyo). Ground tablets was sieved through No. 60 mesh sieve (Tsutsui Scientific Instruments CO., Ltd.). A definite amount of ground tablets (as $600 \mathrm{mg}$ of rebamipide) was weighted. Citric acid (Kozakai Pharmaceutical CO., Ltd., Tokyo), L-glutamine (Nipro Corporation, Osa- 
ka), and simple syrup (Maruishi Pharmaceutical Co., Ltd., Osaka) were added to the sieved powders as flavoring agents. In addition, Toromeiku ${ }^{\circledR}$ clear (Meiji Co., Ltd., Tokyo) was added as a thickening agent. A volume of $2 \mathrm{~mL}$ of preservatives was prepared by dissolving methyl $p$-hydroxybenzoate (Kanto Chemical CO., Inc., Tokyo) and propyl $p$ hydroxybenzoate (Kanto Chemical CO., Inc., Tokyo) in ethanol (Yoshida Pharmaceutical Co., Ltd., Tokyo) and to the formulation. Further, distilled water (Otsuka Pharmaceutical Factory, Inc., Tokyo) was added to prepare a total of $300 \mathrm{~mL}$ of the formulation (Table 1).

The formulation was stored under refrigeration for a period of no longer than $21 \mathrm{~d}$. Citric acid, L-glutamine, and simple syrup were used to add a lemon flavor to mask the bitter taste of the active ingredient, rebamipide. Lemon flavor was selected because a sour taste is suitable for masking a bitter taste, which was based on a study reporting the selection of flavoring agents. ${ }^{27)}$ Toromeiku ${ }^{\circledR}$ clear is a food additive used to add thickness to food. Unlike carboxycellulose, Toromeiku ${ }^{\circledR}$ clear has good solubility and dissolves in water at room temperature. Toromeiku ${ }^{\circledR}$ clear was added to extend the retention time of the ingredient in the mouth by increasing the viscosity of the rebamipide mouthwash to strengthen adhesion to the oral mucosa.

Study Design The rebamipide mouthwash was administered to patients who developed stomatitis after undergoing cancer chemotherapy and provided consent. The administration period was set as $14 \mathrm{~d}$. We asked the patients to maintain a stomatitis diary from $1 \mathrm{~d}$ of administration to $14 \mathrm{~d}$. The doctors conducted an interview regarding the oral state at a follow-up visit after $28 \mathrm{~d}$. The doctors made an appropriate judgment regarding the continuous administration of the rebamipide mouthwash until $28 \mathrm{~d}$ of treatment, as necessary.

Recently, because most cancer chemotherapy sessions tend to be performed on an outpatient basis, it is difficult for medical professionals to make daily observations. We asked the patients to maintain a diary on stomatitis so that we could grasp the diagnostic findings and changes in pain or recuperation. The stomatitis diary included the stomatitis survey, number of times the patient gargled, and stomatitis observations on the figure provided. The stomatitis survey comprised our original survey created by modifying
Table 2. Stomatitis Survey

\begin{tabular}{lll}
\hline \hline \multicolumn{1}{c}{ Oral state (A) } & Pain level (B) & Eating (C) \\
\hline 0 No symptoms & 0 No pain & $\begin{array}{l}\text { 0 Able to eat nor- } \\
\text { mally }\end{array}$ \\
$1 \begin{array}{l}\text { Red parts are } \\
\text { present }\end{array}$ & $\begin{array}{l}\text { Sore with } \\
\text { irritants }\end{array}$ & $\begin{array}{l}\text { Able to eat soft } \\
\text { food }\end{array}$ \\
$\begin{array}{l}\text { Red parts and } \\
\text { white parts are } \\
\text { present }\end{array}$ & $2 \begin{array}{l}\text { Sore with any } \\
\text { food }\end{array}$ & $2 \begin{array}{l}\text { Distressing even } \\
\text { with soft food }\end{array}$ \\
$3 \begin{array}{l}\text { Extended white } \\
\text { parts }\end{array}$ & $3 \begin{array}{l}\text { Pain while } \\
\text { awake }\end{array}$ & $3 \begin{array}{l}\text { Only able to } \\
\text { drink }\end{array}$ \\
4 Always bleeding & 4 Unable to sleep & $4 \begin{array}{l}\text { Unable to drink } \\
\text { either }\end{array}$ \\
\hline
\end{tabular}

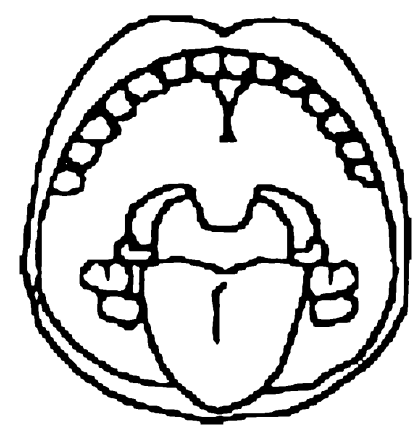

Fig. 1. Intra Oral Observation Chart of Stomatitis

the evaluation criteria on pain and recuperation in the CTCAE Ver. 4.0 in a more specific form. The survey items were divided into (A) oral state, (B) pain level, and $(\mathrm{C})$ diet, and each question was evaluated according to a five-grade scale (Table 2 ). We asked for participants to observe their mouth with using a mirror, and draw on the oral figure provided so that a detailed appearance of the oral mucosa could be recorded (Fig. 1). Combination steroid drugs therapeutically effective for stomatitis and a formulation with sodium azulene sulfonate as a conventional coping strategy were defined as general contraindicated drugs for concomitant administration. Cooling with ice was made acceptable for such combination use.

Dosage and Administration Instructions for administration were to shake the study drug well, take $25 \mathrm{~mL}$ in one or two doses and gargle by moving the mouth for $10 \mathrm{~s}$ so that the entire mouth came in contact with the drug. This procedure was repeated after breakfast, at 10:00 A.M., after lunch, at 03:00 P.M., after dinner, and before bedtime, a total of six times a day for $14 \mathrm{~d}$. Depending on the symptoms, patients were permitted to reduce the number of times of gargling. As a precaution, no eating or gargling of 
Table 3. Stomatitis Evaluation Score

\begin{tabular}{ccc}
\hline \hline Grade & Sum of $(\mathrm{A})+(\mathrm{B})+(\mathrm{C})$ & Evaluation of stomatitis \\
\hline 0 & 0 & No symptoms \\
1 & $1-3$ & Mild symptoms \\
2 & $4-6$ & Moderate symptoms \\
3 & $7-9$ & Severe symptoms \\
4 & $10-12$ & Life-threatening symptoms \\
\hline
\end{tabular}

anything else was allowed for $10 \mathrm{~min}$ immediately after gargling with the study drug.

Endpoints The results of three types of the survey sections (A), (B), and (C) in the stomatitis survey were evaluated as primary endpoints. The observation of stomatitis were evaluated as secondary endpoints.

Evaluation Methods For the evaluation of the treatment response of stomatitis, the total score of the points in the survey sections (A), (B), and (C) was graded using our original evaluation method. This was defined as a stomatitis evaluation score (SES) (Table 3 ). Grade 0 indicates a condition that has no adverse effects on living. Grade 1 indicates a condition that has no adverse effects on living but manifests some symptoms. Grade 2 indicates a condition that has some adverse effects and manifests moderate symptoms. Grade 3 indicates a condition that has adverse effects on living and manifests severe symptoms. Grade 4 indicates a condition that makes normal living difficult and can be life-threatening if it is prolonged. The total scores were classified into the above five grades and evaluated as SESs. Anticancer drug-induced stomatitis results in the appearance of several ulcers distantly located in the mouth. Therefore, using the image analysis software Image ${ }^{28-30}$ ) each area in which stomatitis was observed and recorded by the patient in the figure within the diary provided was measured and then totaled. The total was then compared with the changes in SES.

\section{RESULTS}

Patient Characteristics The subjects consisted of one inpatient and four outpatients, totaling five cases. Table 4 presents the characteristics of the patients. The breakdown of patient characteristics showed that all cases were male, and ages ranged from 62 to 83 years (mean age: 71.6 years). Three patients had rectal cancer, one had colorectal cancer, and one had lung cancer. Cooling with ice was not carried out all patients. Four patients (Patient number; 1, 2, 3, and 5) continued to present with stomatitis following the previous treatment or previous course of chemotherapy. Each of the four patients commenced treatment with the rebamipide mouthwash on the first day of the anticancer drug administration. The previous anticancer drug administration was 2 weeks prior. Patient 4 reinitiated cancer chemotherapy for cancer recurrence and developed stomatitis on $8 \mathrm{~d}$ after starting chemotherapy. The decision to use the rebamipide mouthwash was made on $12 \mathrm{~d}$ after starting chemotherapy. None of the patients used permitted concomitant drugs. Patients 2,3 , and 4 received molecular targeting drugs in conjunction with cancer chemotherapy. The concomitant drug administered to Patients 2 and 3 included bevacizumab, and the concomitant drug administered to Patient 4 was panitumumab. There were no cases of radiotherapy, and no adverse events were observed.

Table 4. Patient Characteristics

\begin{tabular}{|c|c|c|c|c|c|}
\hline Patient No. & 1 & 2 & 3 & 4 & 5 \\
\hline Age (year) & 62 & 83 & 69 & 77 & 67 \\
\hline Gender & Male & Male & Male & Male & Male \\
\hline Cancer type & Rectal cancer & Rectal cancer & Rectal cancer & Lung cancer & Colorectal cancer \\
\hline Cancer chemotherapy & FOLFIRI $^{\mathrm{a}}$ & $\mathrm{XELOX}^{\mathrm{b}}+\mathrm{BV}^{\mathrm{c}}$ & FOLFIRI + BV & DTX $^{\mathrm{d}}$ monotherapy & $\mathrm{XELOX}+\mathrm{Pmab}^{\mathrm{e}}$ \\
\hline $\begin{array}{c}\text { Course } \\
\text { (day of the course) }\end{array}$ & $\begin{array}{l}\text { 7th course } \\
\text { (1 day) }\end{array}$ & $\begin{array}{l}\text { 1st course } \\
(1 \text { day })\end{array}$ & $\begin{array}{l}\text { 6th course } \\
\text { (1 day) }\end{array}$ & $\begin{array}{l}\text { 1st course } \\
\text { (13 days) }\end{array}$ & $\begin{array}{l}\text { 2nd course } \\
\text { (1 day) }\end{array}$ \\
\hline Patient classification & Outpatient & Outpatient & Outpatient & Inpatient & Outpatient \\
\hline
\end{tabular}

${ }^{a}$ FOLFIRI: Fluorouracil + Levofolinate Calcium + Irinotecan Hydrochloride Hydrate, ${ }^{\mathrm{b}}$ XELOX: Capecitabine+Oxaliplatin, ${ }^{\mathrm{c}}$ BV: Bevacizumab, ${ }^{\mathrm{d}}$ DTX: Docetaxel, e P-mab: Panitumumab. 
(a)

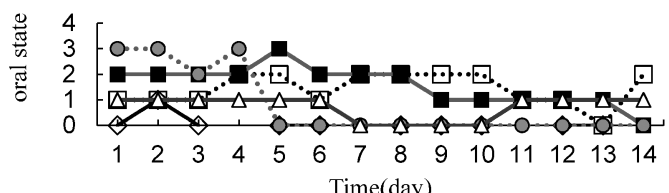

(b)

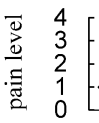

Time(day)

(c)

(d)
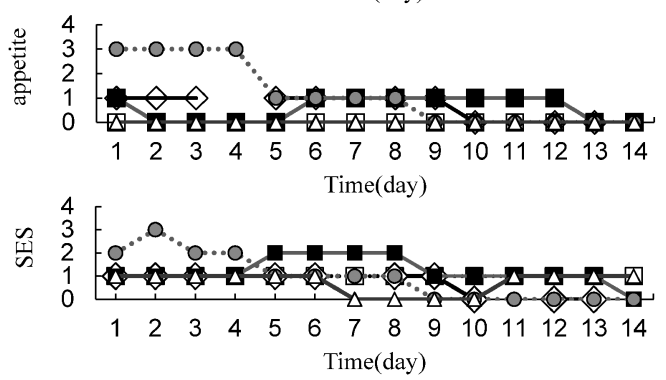

Fig. 2. Changes in the Various Score Evaluated in This Study (a) Oral state, (b) Pain level, (c) Appetite, (d) Stomatitis evaluation score. Individual patients are denoted as follows : $\square:$ Patient $1 ; \diamond:$ Patient 2; : Patient 3; : Patient 4 ; and $\triangle$ : Patient 5.

Changes in the Various Score Evaluated in This Study Figure 2 shows changes in the various score evaluated over the $14 \mathrm{~d}$ of treatment with the rebamipide mouthwash. Patients that the score of (A) was high points did not necessarily had high points of (B) or $(\mathrm{C})$.

SES became 0 in three patients (Patients 2, 3, and 4) by $14 \mathrm{~d}$ following treatment with the rebamipide mouthwash. Moreover, SES did not become 0 within $14 \mathrm{~d}$ in Patients 1 and 5, but the report to the doctor at the follow-up revealed the improvement or absence of symptoms.

Three patients exhibited increases in SES during the study period. Patient 3 showed the increased SES on 5 d compared to that at the beginning of the treatment. However, the score had become 0 by $14 \mathrm{~d}$. Patient 4 had an increase in SES on $2 \mathrm{~d}$; however, afterward the score rapidly decreased, turning to 0 on $7 \mathrm{~d}$. SES of Patient 5 became 0 on $7 \mathrm{~d}$ but increased again from 10 d.

The medical records of Patient 1 showed no change in SES from a score of 1 over $14 \mathrm{~d}$. It was revealed that he was dementia, because one of his family members had attended a medical consultation regarding the Patient 1's dementia.

Patients 2, 3, and 5 were continuously administered the rebamipide mouthwash during the follow-up period. Although there were no unresolved cases or cases considered to require continuous treatment, it was decided to continue the treatment with palliative consideration for the patients who wished to receive it. No recurrence of stomatitis was found in Patient 2 and 3 during the follow-up observation, confirming preventive effects. Patient 5 did not develop mucositis (e.g., an ulcer) but complained of a sensation of discomfort over the entire tongue.

Relationship between SES and the Area of Stomatitis The observation study was carried out by cooperating of Patient 1, 3, and 5. Figure 3 shows the example photographs of the stomatitis area illustrated by patient 5 , and the circumscribed images by ImageJ. Figure 4 shows the change of the area of stoma- (a)

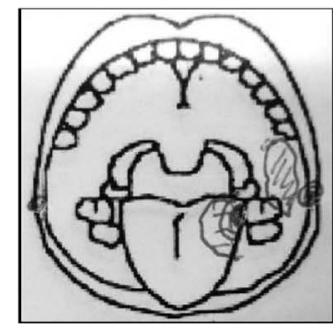

(b)

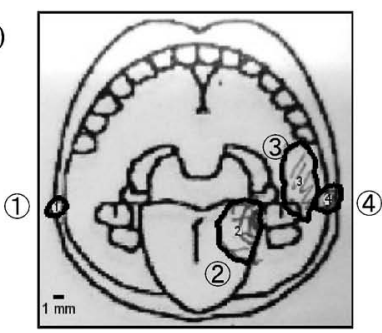

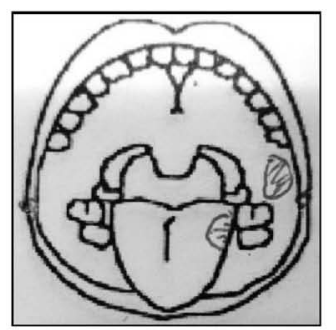

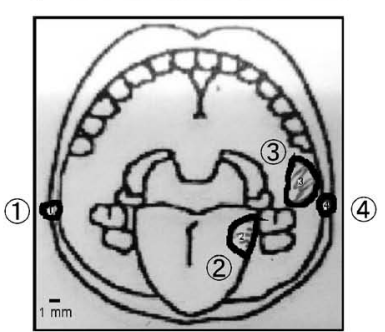

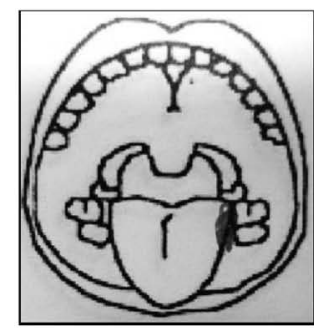

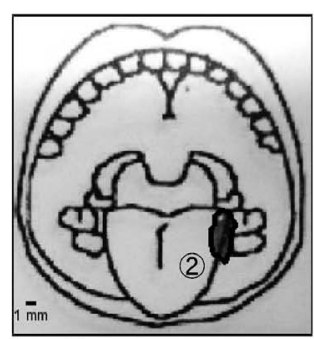

Fig. 3. The Photographs of the Stomatitis Area Illustrated by Patients (a) and the Circumscribed Images by ImageJ (b) (1)-(4) : Areas of stomatitis. 


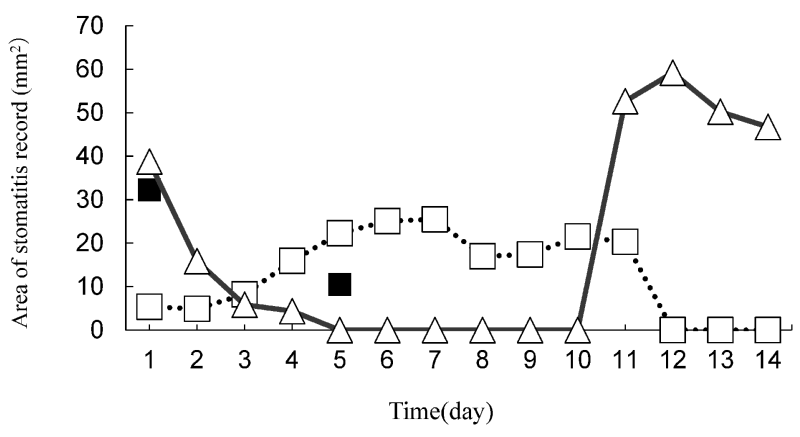

Fig. 4. The Change of the Area of Stomatitis Calculated with Image J

$\square:$ Patient 1; $\mathbf{\square}$ : Patient 3; and $\triangle$ : Patient 5 .

titis calculated with ImageJ. Figure 5 shows the relationship between the stomatitis evaluation score and the area of stomatitis in Patient 5 .

No changes were observed in SES during the early stages of the administration period shown as period " a" in Fig. 5. However, the patient's self-observation demonstrated a gradual reduction in the area of stomatitis. Stomatitis and the symptoms both disappeared on $7 \mathrm{~d}$. Despite this, SES increased again during the period of " $b$ " in Fig. 5 and the area of stomatitis in the extended observation. An ulcer, erythema, or another similar condition was absent during the visual inspection at the time of resuming the survey sheets. The patient stated that it was not sore but that they felt discomfort in the form of numbness or a sensation of food touching the affected site.

\section{DISCUSSION}

Symptoms of stomatitis observed were haphalgesia, bleeding, xerostomia, inflammation of the oral mucosa, trismus, dysarthria, taste disorder, and pain caused by cold and hot water. Such distress may affect conversation with family, which can become a dose- limiting factor of cancer chemotherapy. ${ }^{31)}$ This study aims to contribute to relieving the pain and suffering of patients for whom chemotherapy has been discontinued due to stomatitis or who have continued to undergo cancer chemotherapy while receiving symptomatic treatment for stomatitis. Recent remarkable advances in cancer treatment are making rapid progress. Novel approaches for the prevention and reduction of adverse events should be proposed to ensure that patients, who are to be beneficiaries of the efficacy of the ever-progressing treatment, are not at a disadvantage.

The onset of stomatitis usually occurs between a few days to $10 \mathrm{~d}$ after the administration of anticancer drugs and then gradually improves over 2 to 3 weeks. ${ }^{32)}$ In many cases at our hospital, spontaneous recovery did not occur following the administration of anticancer drugs $14 \mathrm{~d}$ after the previous administration. Therefore, the observation period for the rebamipide mouthwash was set to $14 \mathrm{~d}$. Moreover, the follow-up period was set to $28 \mathrm{~d}$ after administration because cancer chemotherapy patients at our hospital typically visit our hospital once every $14 \mathrm{~d}$.

SES became 0 within $14 \mathrm{~d}$ of treatment in Patients 2,3 , and 5 who had undergone the same or another form of chemotherapy before the start of the rebamipide mouthwash treatment and continued to experience stomatitis at the beginning of treatment.

Two patients whose SES did not become 0 within $14 \mathrm{~d}$ did not exhibit mucositis, which was present at the beginning of treatment when performing an oral observation at the time of resuming the stomatitis diary. They also reported an improvement at follow-up. The above findings suggest that the use of the rebamipide mouthwash is efficacious for the treatment of stomatitis that have already developed from exposure

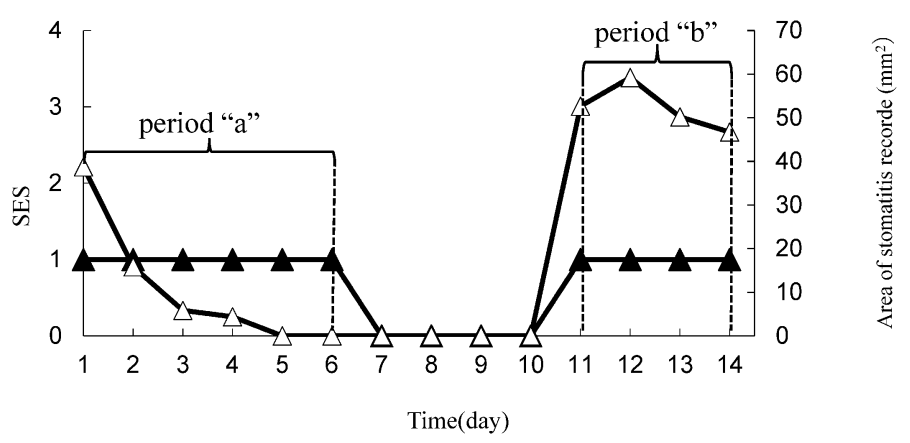

Fig. 5. The Relationship between the Stomatitis Evaluation Score and the Area of Stomatitis in Patient 5

$\boldsymbol{\Delta}$ denotes the stomatitis evaluation score and $\Delta$ denotes the area in the stomatitis observation chart, which was calculated using the imaging analysis software Image J. 
to anticancer drugs.

Three cases in this study also received treatment with molecular targeting drugs. Molecular targeting drugs have different targets to reduce a tumor depending on the type of cancer. Combination therapy of XELOX (Capecitabine + Oxaliplatin) and bevacizumab was administered to Patient 2. According to one report, the incidence of stomatitis was $22.4 \%$ following monotherapy with XELOX and $28.9 \%$ after combination therapy with XELOX and bevacizumab, indicating that the incidence of stomatitis was slightly higher when XELOX was concomitantly used. ${ }^{33)}$ Combination therapy of FOLFIRI (Fluorouracil+ Levofolinate Calcium + Irinotecan Hydrochloride Hydrate) and bevacizumab was administered to Patient 3. Although there have been no reports of directly comparing FOLFIRI monotherapy with combination therapy, the fact that one adverse reaction to bevacizumab is gastrointestinal bleeding suggests that combination therapy could exacerbate oral mucositis. Because SES became 0 in two patients who underwent combination therapy within $14 \mathrm{~d}$, it appeared that the rebamipide mouthwash exhibited efficacy in combination therapy with chemotherapy and bevacizumab.

Patient 3, who exhibited an increase in SES on Day 5 from the start of the treatment, oral state score decreased and ulcers improved but his diet score increased. Adverse reactions of nausea and vomiting are often observed in cancer chemotherapy cases. Thus, the increase in SES was thought to be indicative not of stomatitis but anorexia due to cancer chemotherapy.

After treatment, it was found that the one patient who exhibited no changes in SES was suspected of having dementia according to medical records. Thus, patient's self-evaluation was considered unreliable. Therefore, the selection method of the subjects requires careful consideration in the future.

Using the image analysis software ImageJ, changes in the area measurement of the oral observations in the figure provided were compared with changes in SES. Results show that reduction in the area of stomatitis was observed even when no changes in SES were found. It appeared that ImageJ is useful to evaluate the effectiveness of rebamipide mouthwash to stomatitis objectively.

From these results, SES is considered an objective evaluation as it scores the subjective marks obtained from the survey on pain and recuperation, and the observation figure that the patient recorded while looking at a mirror was a direct evaluation. Thus, by combining SES observation and ImageJ, it will be able to gain an understanding of the treatment course of stomatitis that could not be obtained from SES alone. Therefore, this appeared to be an effective method during the follow-up observation of the outpatients.

\section{CONCLUSION}

The above results suggested that the rebamipide mouthwash tends to be effective for the treatment of stomatitis caused by cancer chemotherapy. In this study, the efficacy of the rebamipide mouthwash was able to evaluate by outpatients themselves. By combining of the condition of oral cavity, the extent of pain and the situation in feeding, we could propose the Stomatitis Evaluation Score, as a new indication for clarifying the stomatitis. However, the number of data were not sufficient to evaluate the efficacy of rebamipide mouthwash, the move detail investigations for many patients should be required. In the future, we will clarify the effectiveness by increasing the number of cases, identifying the importance of each survey item, and conducting multivariate analysis.

Conflict of Interest The authors declare no conflict of interest.

\section{REFERENCES}

1) Naidu M. U., Ramana G. V., Rani P. U., Mohan I. K., Suman A., Roy P., Neoplasia, 6, 423-431 (2004).

2) Parkhill A. L., J. Pharmacovigil., 1, 112 (2013).

3) Keefe D. M., Schubert M. M., Elting L. S., Sonis S. T., Epstein J. B., Raber-Durlacher J. E., Migliorati C. A., McGuire D. B., Hutchins R. D., Peterson D. E., Cancer, 109, 820-831 (2007).

4) Beaven A. W., Shea T. C., Support. Cancer Ther., 4, 188-197 (2007).

5) Multinational Association of Supportive Care in Cancer/International Society of Oral Oncology (MASCC/ISOO) Clinical Practice Guidelines for the Management of Mucositis Secondary to Cancer Therapy: 〈http://www. mascc.org/mucositis-guidelines $\rangle$, cited 10 December, 2016. 
6) Mahood D. J., Dose A. M., Loprinzi C. L., Veeder M. H., Athmann L. M., Therneau T. M., Sorensen J. M., Gainey D. K., Mailliard J. A., Gusa N. L., J. Clin. Oncol., 9, 449-452 (1991).

7) Cascinu S., Fedeli A., Fedeli S. L., Catalano G., Eur. J. Cancer B Oral. Oncol., 4, 234-236 (1994).

8) Coda B. A., O'Sullivan B., Donaldson G., Bohl S., Chapman C. R., Shen D. D., Pain, 72, 333-346 (1997).

9) Yasuno N., Watanabe S., Kanda S., Kizu J., Tsuchiya M., Nishitani A., Ono H., Imai K., Ishio K., Iinuma T., Jpn. J. Hosp. Pharm., 21, 327-334 (1995).

10) Momo K., Yakugaku Zasshi, 135, 931-935 (2015).

11) Loprinzi C. L., Cianflone S. G., Dose A. M., Etzell P. S., Burnham N. L., Therneau T. M., Hagen L., Gainey D. K., Cross M., Athmann L. M., Fischer T., O’Connell M. J., Cancer, 65, 1879-1882 (1990).

12) Tsavaris N. B., Komitsopoulou P., Tzannou I., Loucatou P., Tsaroucha-Noutsou A., Kilafis G., Kosmidis P., Sel. Cancer Ther., 7, 113117 (1991).

13) Elzawawy A., Oncology, 48, 282-284 (1991).

14) Kohri N., Ozawa T., Takasaki M., Eguchi H., Miwa K., Numa J., Abe M., Yakuzaigaku, 61, 34-35 (2001).

15) Yosano A., Nomura T., Shibahara T., Hayashi K., Morituka M., Noma H., J. Jpn. Oral Muco. Membr., 11, 16-20 (2005).

16) Ishii N., Kawano Y., Suzuki M., Komoda M., Makino K., Hanawa T., J. Pharm. Palliat. Care Sci., 9, 87-91 (2016).

17) Hanawa T., Nakazawa M., Mohri K., Ito A., Tsuchiya T., Suzuki M., Hanawa K., Kawata K., Nakajima S., Yakuzaigaku, 60, 175-182 (2000).

18) Hanawa T., Kasai I., Mohri K., Ito A., Tsuchiya T., Hanawa K., Kawata K., Suzuki M., Nakajima S., Yakugaku Zasshi, 120, 1209-1216 (2000).

19) Hanawa T., Masuda N., Mohri K., Kawata K., Suzuki M., Nakajima S., Drug Dev. Ind. Pharm., 30, 151-161 (2004).

20) Muroi N., Nishibori M., Fujii T., Yamagata
M., Hosoi S., Nakaya N., Saeki K., Henmi K., N. Engl. J. Med., 337, 1275-1277 (1997) .

21) Ogino K., Hobara T., Ishiyama H., Yamasaki K., Kobayashi H., Izumi Y., Oka S., Eur. J. Pharmacol., 212, 9-13 (1992).

22) Yoshikawa T., Naito Y., Tanigawa T., Kondo M., Arzneimittelforschung, 43, 363-366 (1993).

23) Parvathi Devi M. K., Ramesh D. N. S. V., Koppal S., Byatnal A. R., Rukmangada T., Byatnal A. A., J. Clin. Diagn. Res., 8, ZC119 -ZC122 (2014).

24) Matsuda T., Ohno S., Hirohata S., Miyanaga Y., Ujihara H., Inaba G., Nakamura S., Tanaka S., Kogure M., Mizushima Y., Drugs $R$ D, 4, 19-28 (2003).

25) Kawata K., Hanawa T., Hanawa K., Takamura T., Suzuki M., Nakajima S., lto A., Unezaki S., Takahashi G., Sakayori S., Matsuzaki Z., Okamoto Y., J. New Rem. \& Clin., 50, 273-280 (2001).

26) Shinohara A., Nakamura M., Onikubo T., Nakamura K., Yakugaku Zasshi, 135, 937-941 (2015).

27) Kabeya M., Ina K., Yuasa S., Kikuchi F., Tajiri C., Kato T., Hibi S., Minagawa Y., Furuta R., Kikuchi T., Kanamori T., Kayukawa S., Kataoka T., J. Integr. Oncol., 2, 1-4 (2013).

28) Rasband W. S., ImageJ, U.S. National Institutes of Health, Bethesda, 〈http://imagej. nih.gov/ij/>, 1997-2016.

29) Schneider C. A., Rasband W. S., Eliceiri K. W., Nat. Methods, 9, 671-675 (2012).

30) Abràmoff M. D., Magalhães P. J., Ram S. J., Biophoton. Int., 11, 36-42 (2004).

31) Sonis S. T., Elting L. S., Keefe D., Peterson D. E., Schubert M., Hauer-Jensen M., Bekele B. N., Raber-Durlacher J., Donnelly J. P., Rubenstein E. B., Cancer, 100, 1995-2025 (2004).

32) Pico J. L., Avila-Garavito A., Naccache P., Oncologist, 3, 446-451 (1998).

33) Cassidy J., Clarke S., Díaz-Rubio E., Scheithauer W., Figer A., Wong R., Koski S., Lichinitser M., Yang T. S., Rivera F., Couture F., Sirzén F., Saltz L., J. Clin. Oncol., 26, 2006-2012 (2008). 